\title{
Solar Roof Top Generation, Marginal Cost, Financial Impacts on the Utility of Sri Lanka
}

\author{
J. G. L. S. Jayawardena ${ }^{1}$, U. Anura Kumara ${ }^{1} \&$ M. A. K. Sriyalatha ${ }^{1}$ \\ ${ }^{1}$ University of Sri Jayewardenepura, Sri Lanka \\ Correspondence: J. G. L. S. Jayawardena, University of Sri Jayewardenepura, Sri Lanka. Tel: 94-7-1999-4133. \\ E-mail: sulakshana@powermin.gov.lk
}

Received: June 8, 2019

Accepted: July 8, 2019 Online Published: July 30, 2019

doi:10.5539/jsd.v12n4p128

URL: https://doi.org/10.5539/jsd.v12n4p128

\begin{abstract}
The intensity of solar radiation in Sri Lanka is $1,247-2,106 \mathrm{kWh} / \mathrm{m} 2$ per annum (SEA, 2014). There are existing solar generation capacities of $177 \mathrm{MW}$ by using solar roof top systems and $51 \mathrm{MW}$ of the utility scale solar plants in the country as at $28^{\text {th }}$ March 2019. The Government of Sri Lanka(GOSL) introduce Building Integrated Photo Voltaic program since 2009 basically to bank the surplus of electricity units with the Utility. In 2016 GOSL introduced cash payback method for surplus energy generated by Roof Top Solar installations. Some of the stakeholders of the electricity sector argue that the Roof Top Solar generation program has negative financial impact on the financial position of the utility. The impact of the Solar Roof Top program on revenue of the Utility and the customer tariff system has been studied. Results show that Feed in Tariff of the Solar Roof Top is comparatively low with most of the thermal power generation. According to the findings of the study it can be concluded that the financial impact of the program is beneficial to the economy as a whole, but marginally negative to the short terms cash flow of the utility. Anyhow it is seen that such utility centric negativity can be ameliorated though due tariff structure. The government has to consider about the electricity policy of customer tariff in order to provide the concessions only for the needy people.
\end{abstract}

Keywords: customer tariff, electricity generation marginal cost, electricity utility, financial impacts, solar roof, top systems

\section{Introduction}

Understanding the rooftop PV program is critical for utility generation planning, grid capacity, financing schemes initiatives and shaping of future adaptive energy policies (Wiginton, Nguyen, \& Pearce, 2010). This is applicable for Sri Lankan context and in Sri Lanka there is a good potential for solar generation. Some of the authors classified solar roof top systems as Building Integrated Photovoltaic (BIPV) systems (Yang \& Zou, 2016; Temby et al., 2014) and further they emphasized the BIPV as a promising solution for the clean energy. The main drivers of the rapid development of BIPV are technological advances, project cost reduction and government support for BIPV (Yang \& Zou, 2016) and Temby et al., (2014) has stressed in addition to such factors innovations and common financial mechanism encouraging BIPV capacities. Wong, Barr \& Kalam, (2015) argued that the main driver of the solar roof top systems is environmental aspect. By the study conducted by Abu-Rub et al., (2012), have also pointed out that the environmental aspect of the solar roof top generation. Levi, Economy, O'Neil, and Segal, (2010) stressed the significance of government policies on renewable energy development. Kosugi, Shimoda, and Tashiro, (2019) has stressed the key driver of evolution of residential PV adoption as the public economic support measures. Hence for successfulness of any program government support is very important. Government of Sri Lanka (GOSL) introduced solar roof top program in 2009 under the scheme called solar net metering program. With the implementation of the program $31.825 \mathrm{MW}$ of systems connected by 6,485 customers during the period of 2009-August 2016. That program was energy banking method and there was no funding involvement or financial transaction between Ceylon Electricity Board (CEB) and the customer under the program. Wong et al., 2015 emphasized the requirement of reasonable Feed in Tariff (FIT) for Solar Roof Top generation to encourage the customers. Roach, (2017) named solar rooftop as personal Power Source competitor for the grid. Solar Photovoltaic(PV) are unconstrained by resource, environmental, material supply, or security issues (Ness and Gurtavo,2017) hence, in 2016 to promote BIPV GOSL has decided to introduced payment method for the customers who generate surplus of electricity by BIPV. This program 
named as "Soorya Bala Sangramaya". Under the "Soorya Bala Sangramaya" program three methods were introduced to suit for the different customer categories and those are called Net metering, Net accounting and Net plus. In the net metering method there is no financial involvement similar to the previously implemented method. However, in the net accounting and net plus method if the customer generates more than that of the requirement he will be paid by the utility i.e. Ceylon Electricity Board (CEB). Under the payment scheme CEB purchases electricity unit at the rate of LKR $22 / \mathrm{kWh}$ in first seven years and 8 years onwards up to 20 years CEB pays LKR15.50/kWh. Under the scheme as at 01.09 .2018 there are $126.9 \mathrm{MW}$ installed capacity established by 11,497 customers. It was stressed that PV energy has great potential to improve the sustainable development (Zandler, Mislimshoeva \& Samimi, (2016) considering that GOSL introduced the "Soorya Bala Sangramaya". However most of the researchers emphasized that BIPV is economically viable, as per the study conducted by Leal, Granadeiro, Azevedo and Boemi, (2015) an energy analysis concluded that building integrated PV, placed on the roof, was not a viable solution, as the issue of PV area, restricted with the total roof area able to accommodate PV panels. But in Sri Lankan context this is doubtful as the program itself has technical requirement that customers can have only the installed capacity which in par with the agreed technical capacity with the utility when they get electricity service connection. That means the customer has to limit the BIPV capacity to the agreed service capacity. Further it is vital to consider the land value and lack of land resources in the country. In the study conducted by Leal et al., (2015) they have not considered the impact of the land usage or optimum usage of lands due to Solar roof top program. Wong et al., (2015) explained the technical challenges of solar roof top system like the distributed nature of these embedded generation, low voltage network limitations and intermittence of the electricity generation. However, this kind of technical issues have to be considered separately for Sri Lankan context.

The objective of the study is to analyze the costs and benefits of Solar roof top program of Sri Lanka in terms of utility perspective.

\section{Methodology}

Secondary data available with Ceylon Electricity Board and Ministry of Power \& Renewable Energy use to analyze the case. In the analysis it was consider the cost of serving of day Peak demand, cost of Solar Roof top generation and implication of prevailing tariff structure of electricity for customers. To analyze the case, the secondary data available with CEB is used. It should be noted that benefits and costs in this research are defined in monetary terms. This paper also provides suggestions to industry stakeholders for integration and collaboration of the BIPV in order to enhance the capacities of solar roof top systems.

\section{Sorya Balasangramaya Program}

\subsection{Financial Involvement of Soorya Bala Sangramaya Program}

Under the scheme there are 11,497 customers who have installed 126.9MW of solar roof top systems as at 01.11.2018 as follows.

Table 1. BIPV systems under "Soorya Bala Snagaramaya" Program up to 31.10.2018

\begin{tabular}{lrrc}
\hline Method & Net Metering & Net Accounting & \multicolumn{2}{c}{ Net Plus } \\
\hline No. of installations & 6282 & 4,779 & 436 \\
Capacity & 58.05 & 30.27 & 38.58 \\
\hline
\end{tabular}

Source: Ministry of Power \& Renewable Energy, 2018

Still the net metering methodology is popular among the customers. Solar electricity evacuates through the network in the day time as there is no storage facility in the system. Under the "Soorya Bala Sangaramaya program" payment mechanism is involved only with Net Accounting and Net Plus schemes. Most of the time customers would generate electricity by Solar roof top systems and evacuate the power. The solar production occurs during the daytime, and has a natural peak shaving affect and also load factor improvement (Hanzlik,2010). This can be observed in Sri Lanka, basically in Sri Lanka there is a peak demand during the daylight hours, with the Solar generation that demand can be reduced. The above three schemes are can briefly be explained as follows.

\subsubsection{Net Metering}

The customer generates electricity using solar panels on their roof tops and connected to the grid. No payment is 
made for the excess electricity supplied and credit for future use. The customer has to pay only for the net amount of electricity that he has consumed. If the amount of electricity generates from solar facility can carry forward the balance and consume it in the months forthcoming.

\subsubsection{Net Accounting}

Customer can generate electricity from solar roof top facilities and if the number of units exceed the amount consumed the customer will be paid LKR22.00/kWh (USD 12 Cents) during the first seven years and $8^{\text {th }}$ year onwards CEB purchased such electricity at the rate of LKR15.50/kWh (USD 9 Cents). If the consumption is greater than the generation customer has to pay for the electricity as per the existing tariff

\subsubsection{Net Plus}

In this method there is no relationship with electricity consumption of the customer and the electricity generation. The customer has to pay for the electricity consumed according to the existing tariff and CEB will pay for the total amount of electricity generated similar to the Net Accounting system

The selection of the Solar Roof top generation method is based on customers' preference. The calculation of Feed in Tariff for Solar Roof Top Systems done based on the following parameters.

Table 2. Input parameters and values for export tariff calculation

\begin{tabular}{ll}
\hline Input Parameter & Description \\
\hline Cost of Systems & PV part 0.5 USD/W, Inverter $0.3 \mathrm{USD} / \mathrm{W}$, BoS $0.275 \mathrm{USD} / \mathrm{W}$ \\
Panel Life & 20 years, Linear degradation to reach $85 \%$ at $20^{\text {th }}$ year \\
Inverter Life & Replaced once, on $11^{\text {th }}$ year \\
Annual Plant Factor & $16 \%$ \\
Grid Availability & $99 \%$ \\
Cost of debt & AWPLR $+3 \%$ taken as $18.39 \%$ \\
Cost of Equity & Latest Ten year Bond rate $(12.5 \%$ on 2016 July 15$)+3.0 \%$,taken as $15.5 \%$ \\
Debt Equity Ratio & $75: 25$ \\
Tenure of Debt & 5 years, no grace \\
O \& M Cost & $0.5 \%$ of Capital Cost per Year, Escalated at $4.98 \%$,the five year average inflation \\
Parity & rate from July 2011 June 2016 \\
\hline
\end{tabular}

Source: Tariff Review Committee Report 2016

The tariff recommended by the tariff committee is 19.82per kWh of export electrical energy. If there is changes in the input parameters, the tariff has to be revisited and recalculated. Based on this flat tariff two tier tariff structure was introduced as customers need higher income or financial income for loan repayment and reasonable income.

Figure 1 shows the daily demand curve of the power system for the period of year 2015 to 2018 of Sri Lanka. 


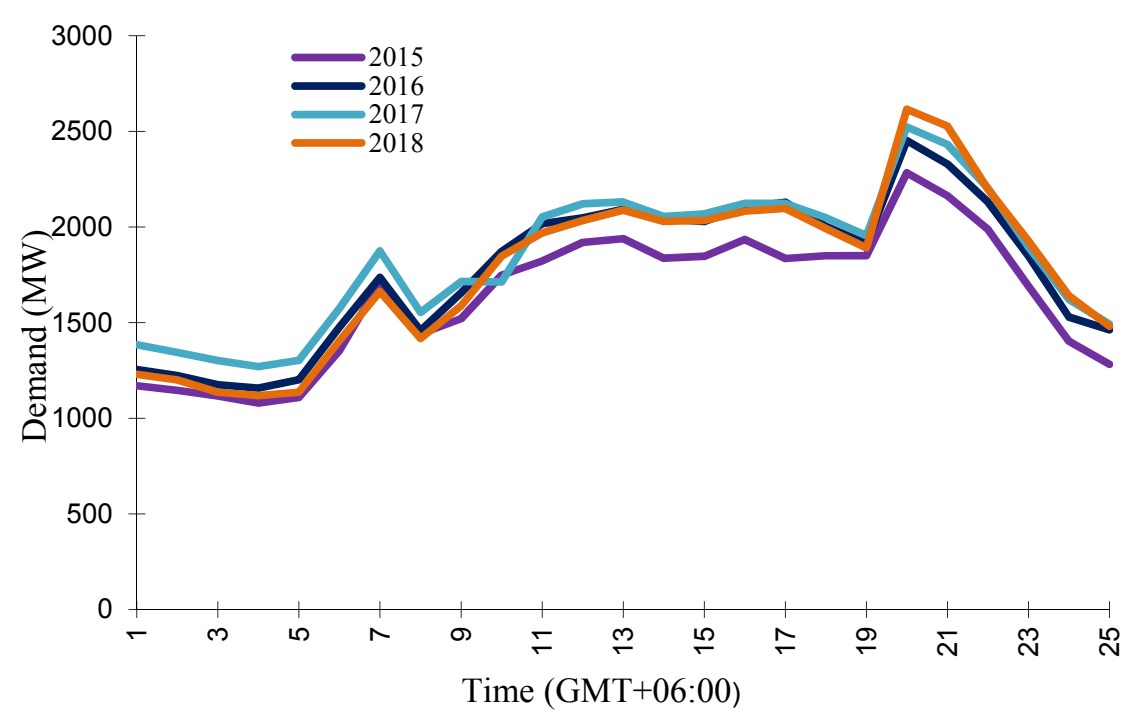

Figure 1. Demand curve of Sri Lanka

As per the above figure it can be identified that there are two significant peaks in during the day time and during the night. The day peak is approximately $2100 \mathrm{MW}$ and the night peak is $2600 \mathrm{MW}$. The system valley occurs during the early hours of the day with a load of approximately 1100MW.The average load during the solar hours of the day is 1900MW. In the peak it is critical to meet demand using existing capacities. Hammon, (2010) explains the problem of peak demand in three-fold way including environment pollution, cost and system stability. According to him power system needs "peaker power plants" to meet peak demand which is inefficient and expensive. However, if utility can reduce the peak demand they can get rid of such polluted expensive power plants. One of the method is to promote solar roof top systems among the customers. To promote Solar roof top systems among the customers, depend on the cost effectiveness of the Solar Generation Systems and it depends highly on the national electricity price level and solar resources (Mondol \& Hillenbrand,2014). This is applicable for the development of Solar systems in the Country, as if the customer can recover the investment within shorter period that will be encouraging to join with the program. Basically when the Feed in Tariff(FIT) is high and plant factor high the customers can recover the investment within a shorter period.

In Sri Lanka Months of February, March and April consider as the dry period of a year. During that period 80-85\% of day peak is served by thermal power plants. 
Table 3. Ceylon electricity board generation facilities including independent power producers (Dry weather scenario)

\begin{tabular}{ccc}
\hline Power Plant & Available Capacity(MW) & Cost LKR/kWh \\
\hline Lakvijaya Coal power plant & $810 \mathrm{MW}$ & 12.09 \\
Kerawalapitiya Power Plant & $270 \mathrm{MW}$ & 29.85 \\
AES Kelanithissa & $130 \mathrm{MW}$ & 23.34 \\
ACE Embilipitiya & $93 \mathrm{MW}$ & 23.06 \\
Kelanithissa Gas turbine & $64 \mathrm{MW}$ & 62.71 \\
Kelanithissa Combined Cycle Gas Power Plant & $110 \mathrm{MW}$ & 25.16 \\
Kelanithissa Combined Cycle Steam Power & & 37.51 \\
Plant & & \\
Agreko & $60 \mathrm{MW}$ & $33.03 *$ \\
Sapugaskanda A & $64 \mathrm{MW}$ & 29.31 \\
Sapugaskanda B & $72 \mathrm{MW}$ & 25.42 \\
Uthuru Janani & $21 \mathrm{MW}$ & 29.50 \\
Power Barge & $60 \mathrm{MW}$ & 20.35 \\
\hline
\end{tabular}

*Supplementary Power Plants added to the system on temporary basis for 6-month period and now those have been disconnected as Power Purchase Agreement completed.

Source: Public Utilities Commission of Sri Lanka and CEB, 2017

However, during the wet weather condition hydro power generation is used to generate approximately $50 \%$ of total day demand. The merit order based on the cost use to select the power plant to meet incremental demand. Incremental cost of the electricity unit is vital for the selection of power plant to meet the demand. It can be demonstrated as follows.

Table 4. Merit order dispatch and requirement of capacity availability-dry weather scenario

\begin{tabular}{cccc}
\hline Merit order plant & Capacity & Cumulative capacity & Incremental cost \\
\hline Hydro & $440 \mathrm{MW}$ & $440 \mathrm{MW}$ & - \\
Lakvijaya Coal Power Plant & $810 \mathrm{MW} *$ & $1,250 \mathrm{MW}$ & 12.09 \\
Barge Mounted Power Plant & $60 \mathrm{MW}$ & $1,310 \mathrm{MW}$ & 20.35 \\
ACE Embilipitiya & $90 \mathrm{MW}$ & $1,400 \mathrm{MW}$ & 23.06 \\
AES Kelanithissa & $130 \mathrm{MW}$ & $1,530 \mathrm{MW}$ & 23.34 \\
Kelanithissa Combined Cycle Gas Power Plant & $110 \mathrm{MW}$ & $1,640 \mathrm{MW}$ & 25.16 \\
Sapugaskanda B & $72 \mathrm{MW}$ & $1,712 \mathrm{MW}$ & 25.42 \\
Sapugaskanda A & $64 \mathrm{MW}$ & $1,776 \mathrm{MW}$ & 29.31 \\
Uthuru Janani & $21 \mathrm{MW}$ & $1,797 \mathrm{MW}$ & 29.50 \\
Kerawalapitiya & $270 \mathrm{MW}$ & $2,067 \mathrm{MW}$ & 29.85 \\
Aggreco & $60 \mathrm{MW}$ & $2,107 \mathrm{MW}$ & 33.03 \\
Kelanithissa GT & $64 \mathrm{MW}$ & $2,171 \mathrm{MW}$ & 37.51 \\
\hline
\end{tabular}

*Under this calculation it was assumed that 3 units of Coal power plant operate in full capacity. But during past couple of years' unit one availability capacity was 200MW.

Source: CEB and PUCSL, 2017

In the day time the day peak requirement is approximately $2,100 \mathrm{MW}$ and continues the requirement throughout the day time. In dry season, even to meet the capacity of 1400MW CEB has to run the ACE Embilipitiya power 
plant. The day capacity of the dry period is again $2,100 \mathrm{MW}$ and to meet such capacity CEB has to run the plants are having unit cost more than $\mathrm{kWh} 37.00 / \mathrm{kWh}$. The above table shows the ACE Embilipitiya power plant is generating electricity with the marginal cost of $23.06 / \mathrm{kWh}$ which is the marginal plant for solar tariff. In fact, even this is also more than that of solar tariff as solar generation tariff is LKR $22.00 / \mathrm{kWh}$ but which can be considered as the closest marginal cost generator having the cutoff point of Solar generation. Anyhow, since marginal generator in day peak is Kelanithissa GT with an On the other hand, if solar roof top generates electricity the reduction of day demand would reduce the cost of electricity generation from Kelanithissa gas turbine at the rate is LKR37.51/kWh.

The situation in the wet season following table gives the relevant information. We consider the assumption of that hydro contribution is percentage is $50 \%$ of the demand.

Table 5. Merit order dispatch in wet season in the day time

\begin{tabular}{cccc}
\hline Merit order plant & Capacity & Cumulative capacity & Incremental cost \\
\hline Hydro & $1,100 \mathrm{MW}$ & $1,100 \mathrm{MW}$ & - \\
Lakvijaya Coal Power Plant & $810 \mathrm{MW}$ & $1,910 \mathrm{MW}$ & 12.09 \\
Barge Mounted Power Plant & $60 \mathrm{MW}$ & $1,970 \mathrm{MW}$ & 20.35 \\
ACE Embilipitiya & $90 \mathrm{MW}$ & $2,060 \mathrm{MW}$ & 23.06 \\
AES Kelanithissa & $130 \mathrm{MW}$ & $2,190 \mathrm{MW}$ & 23.34 \\
Kelanithissa Combined Cycle Gas Power Plant & $110 \mathrm{MW}$ & $2,300 \mathrm{MW}$ & 25.16 \\
\hline
\end{tabular}

Source: PUCSL and CEB, 2017

According to the table to meet day demand of 2,300MW CEB has to run the power plant which has unit cost of LKR 25.16, comparatively it is higher than the Solar Roof top electricity cost. Normally the plant load factor of the thermal power plant is around $80 \%$. In that context if low cost generation plant shut down for maintenance CEB has to use comparatively expensive unit cost power plant.

CEB tariff structure and cost recovery difficulties.

The number of customers in each category of CEB is as follows.

Table 6. Ceylon electricity board customers

\begin{tabular}{cccccc}
\hline $\begin{array}{c}\text { Tariff } \\
\text { Category }\end{array}$ & Sub groups & $\begin{array}{c}\text { No. of } \\
\text { customers }\end{array}$ & $\begin{array}{c}\text { Percentage out of the } \\
\text { total customers\% }\end{array}$ & $\begin{array}{c}\text { Revenue } \\
\text { category (LKR Mn) }\end{array}$ & $\begin{array}{c}\text { Percentage of total } \\
\text { Revenue \% }\end{array}$ \\
\hline Domestic & $0-30$ & $1,261,930$ & 19.9 & 59,089 & 27.0 \\
& $31-60$ & $1,546,873$ & 24.5 & & \\
& $61-90$ & $1,415,170$ & 22.4 & & 1.9 \\
& $91-120$ & 676,669 & 10.7 & & 14.4 \\
& $121-180$ & 441,549 & 6.9 & 4,206 & 11.0 \\
\hline Industries & Small(I1) & 55,540 & 2.7 & 31,467 & 16.6 \\
& Medium(I2) & 4,885 & 0.9 & 24,021 & 10.0 \\
\hline General & Large(I3) & 269 & 0.1 & 36,321 & 3.6 \\
\hline Small(G1) & 662,436 & Negli. & 21,826 & 0.0003 \\
\hline Hetels & Medium(G2) & 4,497 & 10.7 & 7,842 & 1.4 \\
& Large & 129 & 0.1 & 61 & 0.8
\end{tabular}

Negli. -Negligible Source: CEB, 2017 
The other argument is due to the solar roof top program most of the high end customers would use less electricity units and therefore the income will be reduced and the amount of cross subsidiaries will be reduced. According to the Sinha, (2005) cross subsidiary is difference of cost to serve and the tariff charged from the customer. The Tariff structure is the system of relative prices paid by different categories of consumers(Kristov,1995). In Sri Lankan tariff structure there are different tariff categories and based on the requirement based on the GOSL policy such tariff categorization has been introduced.

Tariff structure of Sri Lanka is as follows.

Table 7. Customer categories, tariff structure of Sri Lanka

\begin{tabular}{|c|c|c|c|}
\hline Tariff Category & Sub groups & Fixed Charge(LKR) & Tariff(LKR/kWh) \\
\hline \multirow[t]{6}{*}{ Domestic } & $0-30$ & 30.00 & 2.50 \\
\hline & $31-60$ & 60.00 & 4.85 \\
\hline & $61-90$ & 90.00 & 10.00 \\
\hline & $91-120$ & 480.00 & 27.75 \\
\hline & $121-180$ & 480.00 & 32.00 \\
\hline & 181 or above & 540.00 & 45.00 \\
\hline \multirow[t]{10}{*}{ Industries } & Small(I1) & Less than $300 \mathrm{kWh}-$ No fixed charge & 10.80 \\
\hline & & 301 or above- 680 & 12.20 \\
\hline & Medium(I2) & Peak & 20.50 \\
\hline & & Day & 11.00 \\
\hline & & Off peak & 6.80 \\
\hline & & $\begin{array}{l}\text { Fixed charge LKR 3,000 and minimum energy } \\
\text { demand LKR 1,100 }\end{array}$ & \\
\hline & Large(I3) & Peak & 23.50 \\
\hline & & Day & 10.25 \\
\hline & & Off Peak & 5.90 \\
\hline & & $\begin{array}{c}\text { Fixed charge LKR 3,000 and minimum energy } \\
\text { demand LKR 1,000 }\end{array}$ & \\
\hline \multirow[t]{10}{*}{ General } & Small(G1) & 240.00 & Up to $300-18.30$ \\
\hline & & & 301 and above- 22.85 \\
\hline & Medium(G2) & Peak & 26.60 \\
\hline & & Day & 21.80 \\
\hline & & Off peak & 15.40 \\
\hline & & $\begin{array}{l}\text { Fixed charge LKR 3,000 and minimum energy } \\
\text { demand LKR 1,100 }\end{array}$ & \\
\hline & Large & Peak & 25.50 \\
\hline & & Day & 20.70 \\
\hline & & Off peak & 14.35 \\
\hline & & $\begin{array}{c}\text { Fixed charge LKR 3,000 and minimum energy } \\
\text { demand LKR 1,100 }\end{array}$ & \\
\hline \multirow[t]{9}{*}{ Hotels } & Small & 600.00 & 21.50 \\
\hline & Medium & Peak & 23.50 \\
\hline & & Day & 14.65 \\
\hline & & Off Peak & 9.80 \\
\hline & & $\begin{array}{l}\text { Fixed charge LKR 3,000 and minimum energy } \\
\text { demand LKR 1,100 }\end{array}$ & \\
\hline & Large & Peak & 22.50 \\
\hline & & Day & 13.70 \\
\hline & & Off Peak & 8.80 \\
\hline & & $\begin{array}{c}\text { Fixed charge LKR 3,000 and minimum energy } \\
\text { demand LKR } 1,100\end{array}$ & \\
\hline
\end{tabular}

Source: Public Utilities of Sri Lanka, 2014 
The electricity tariff is the key area where it creates the primary revenue stream in defining the financial position of the utility. Since the electricity tariff is rather a politicized subject no government would not make the politically unpopular decision to increase the tariff in meeting the cost of the utility. Hence, utility is underpinning to reduce the expenditures and ensure the maximum income through existing tariff structure. If the utility is not in a position to recover the cost through the existing tariff structure interlinking the direct subsidiary and cross subsidiary is the ways to get adequate income to avoid the ill effects of subsidy to the financial position. Lin and Jiang, (2011) stressed that the electricity subsidiary is very vital for sustainable development of energy use. In the above table it can be clear that there are cross subsidiaries within the customer category and among the customer category. The average electricity generation cost of CEB in 2017 was LKR 20.34. However, the average selling price of electricity in 2017 was LKR16.26/kWh in 2017.The average selling price is calculated including the cross subsidiaries. Accordingly, the revenue gap is LKR 4.08/kWh. A significant amount of electricity cross subsidiaries goes to the domestic high end customer category as well due to the nature of the Sri Lankan Tariff structure. This group of customers prefer to have Net metering method for BIPV facility where as they can bring down their electricity cost. This can be illustrated in following table using simple calculation of domestic high end single phase and three phase customer.

Table 8. Hypothetical illustration of high end customers' electricity usage and solar generation

\begin{tabular}{cccccccc}
\hline $\begin{array}{c}\text { Customer } \\
\text { Group }\end{array}$ & $\begin{array}{c}\text { Consumption } \\
\mathbf{( k W h )}\end{array}$ & $\begin{array}{c}\text { Electricity } \\
\text { Bill (LKR)if } \\
\text { BIPV not } \\
\text { there }\end{array}$ & $\begin{array}{c}\text { Solar } \\
\text { Capacity } \\
\mathbf{( k W )}\end{array}$ & $\begin{array}{c}\text { Solar } \\
\text { Generation } \\
\mathbf{( k W h ) *}\end{array}$ & $\begin{array}{c}\text { Net } \\
\text { Units } \\
\mathbf{( k W h )}\end{array}$ & $\begin{array}{c}\text { Solar } \\
\text { Payment } \\
\text { (LKR) }\end{array}$ & $\begin{array}{c}\text { Loss of } \\
\text { Revenue* }\end{array}$ \\
\hline $\begin{array}{c}\text { Domestic } \\
\text { High End }\end{array}$ & 200 & $4,963.50$ & 7 & 770 & 570 & 12,540 & $4,932.00$ \\
$\begin{array}{c}\text { Customers } \\
\text { Single Phase }\end{array}$ & & & & & & & \\
& 250 & $7,213.50$ & & 770 & 520 & 11,440 & $6,165.00$ \\
& 300 & $9,463.50$ & & 770 & 470 & 10,340 & $7,398.00$ \\
& 350 & $11,713.50$ & & 770 & 420 & 9,240 & $8,631.00$ \\
& 400 & $13,963.50$ & & 770 & 370 & 8,140 & $9,864.00$ \\
Domestic & 200 & $4,963.50$ & 20 & 2,200 & 2000 & 44,000 & $4,932.00$ \\
High End & & & & & & & \\
Customers & & & & & & & \\
Three Phase & & & & 2200 & 1950 & 42,900 & $6,165.00$ \\
& 250 & $7,213.50$ & & 2200 & 1900 & 41,800 & $7,398.00$ \\
& 300 & $9,463.50$ & & 2200 & 1850 & 40,700 & $8,631.00$ \\
& 350 & $11,713.50$ & & 2200 & 1800 & 39,600 & $9,864.00$ \\
\hline
\end{tabular}

*Considering Average generation cost is LKR20.34/kWh and Tariff is LKR45.00/kWh, the difference is LKR 24.66 .

Source: Ceylon Electricity Board

In the high end electricity customer group there is no negative impact of generation of electricity from the BIPV. However, the impact is the loss of revenue by the CEB. Above table gives the calculation of the electricity usage and BIPV generation based on the assumptions of Single Phase and Three Phase high end customers of the electricity usage of 200-400 $\mathrm{kWh}$. This can be further worse those customers use same amount of electricity in the night and contribute to night peak unless they follow certain Demand Side Management (DSM) initiatives.

But in the night peak the merit order dispatch is as follows. 
Table 9. Merit order dispatch in dry season in the night time

\begin{tabular}{cccc}
\hline Merit order plant & Capacity & Cumulative capacity & Incremental cost \\
\hline Hydro & $440 \mathrm{MW}$ & $440 \mathrm{MW}$ & - \\
Lakvijaya Coal Power Plant & $810 \mathrm{MW} *$ & $1,250 \mathrm{MW}$ & 12.09 \\
Barge Mounted Power Plant & $60 \mathrm{MW}$ & $1,310 \mathrm{MW}$ & 20.35 \\
ACE Embilipitiya & $90 \mathrm{MW}$ & $1,400 \mathrm{MW}$ & 23.06 \\
AES Kelanithissa & $130 \mathrm{MW}$ & $1,530 \mathrm{MW}$ & 23.34 \\
Kelanithissa CCG Power Plant & $110 \mathrm{MW}$ & $1,640 \mathrm{MW}$ & 25.16 \\
Sapugaskanda B & $72 \mathrm{MW}$ & $1,712 \mathrm{MW}$ & 25.42 \\
Sapugaskanda A & $64 \mathrm{MW}$ & $1,776 \mathrm{MW}$ & 29.31 \\
Uthuru Janani & $21 \mathrm{MW}$ & $1,797 \mathrm{MW}$ & 29.50 \\
Kerawalapitiya & $270 \mathrm{MW}$ & $2,067 \mathrm{MW}$ & 29.85 \\
Aggreco & $60 \mathrm{MW}$ & $2,107 \mathrm{MW}$ & 33.03 \\
Kelanithissa GT & $64 \mathrm{MW}$ & $2,171 \mathrm{MW}$ & 37.51
\end{tabular}

Source: Ceylon Electricity Board

Table 10. Merit order dispatch in wet season in the day time

\begin{tabular}{cccc}
\hline Merit order plant & Capacity & Cumulative capacity & Incremental cost LKR \\
\hline Hydro & $1,100 \mathrm{MW}$ & $1,100 \mathrm{MW}$ & - \\
Lakvijaya Coal Power Plant & $810 \mathrm{MW}$ & $1,910 \mathrm{MW}$ & 12.09 \\
Barge Mounted Power Plant & $60 \mathrm{MW}$ & $1,970 \mathrm{MW}$ & 20.35 \\
ACE Embilipitiya & $90 \mathrm{MW}$ & $2,060 \mathrm{MW}$ & 23.06 \\
AES Kelanithissa & $130 \mathrm{MW}$ & $2,190 \mathrm{MW}$ & 23.34 \\
Kelanithissa Combined Cycle Gas Power Plant & $110 \mathrm{MW}$ & $2,300 \mathrm{MW}$ & 25.16
\end{tabular}

Source: Ceylon Electricity Board

To meet the day demand, it is necessary to have at least 2,200 MW capacity. Following graph shows the changes of day demand during the last 4 years.

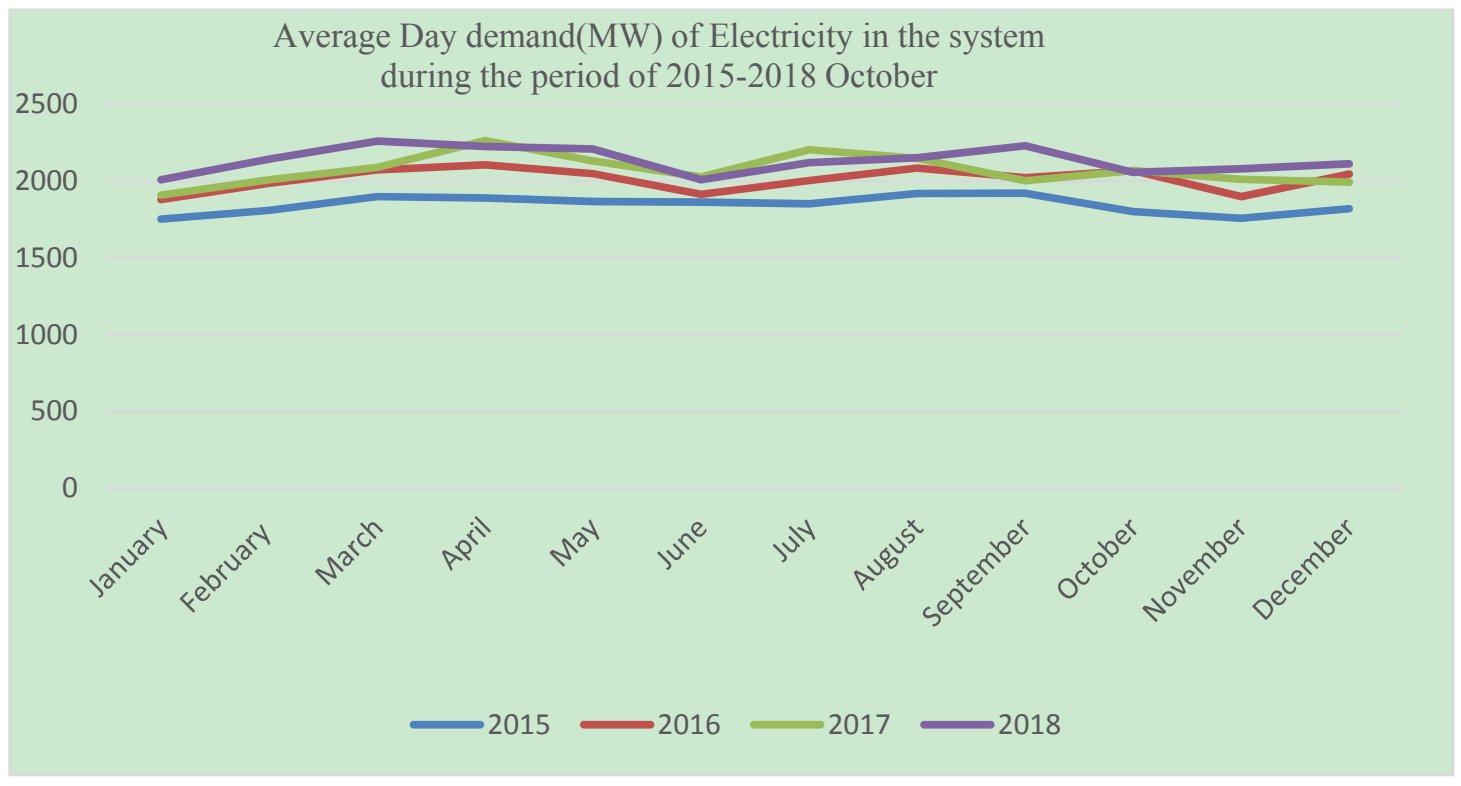

Figure 2. Average Day demand(MW) of Electricity in the system during the period of 2015-2018 October Source: Ceylon Electricity Board 
Figure 2 shows the demand growth of each year during the last 4 years. It depicted that the growth is more or less similar in each year. According to the graph it can be observed that during the period of January to April there is an increase of demand and July August period.

CEB is collecting the revenue through each distribution licensees. However, the financial position of CEB is not a sound one as they are still running with short of funds to meet the expenditure in the business. It can be given in the following table for last four years.

Table 11. Financial position, revenue, expenditure, GOSL subsidiary of CEB

\begin{tabular}{llccc}
\hline Year & Cost & Revenue & Deficit & Government \\
& LKR Mn. & LKR Mn. & LKR Mn. & subsidiary LKR Mn. \\
\hline 2013 & 178,666 & 200,891 & 20,900 & \\
2014 & 221,266 & 206,346 & $(13,897)$ & \\
2015 & 177,645 & 198,362 & 20,844 & 6,000 \\
2016 & 231,079 & 214,953 & $(16,389)$ & $(47,299)$ \\
2017 & 272,962 & 225,894 & $(26,805)$ & \\
2018 & 270,943 & 244,138 & & \\
\hline
\end{tabular}

Source: CEB, 2018

It can be observed that the deficit between the expenditure and the revenue have not been met by CEB in the period of 2014-2017(CEB statistics) except few wet years. Hence CEB has to borrow short term loans at considerably high interest rate. It looks that CEB is getting less revenue from the high end customers who pay high tariff, due to solar roof top program and they bring down their electricity consumption enabling them to come to the low tariff categories. If the utility is not getting sufficient revenue to recover the expenditures, it may cause again a social cost due to unhealthy financial situation of public sector utility (Hossain, 1993). This is a current and pertinent issue CEB needs to address. Further Hossain, (1993) stressed that the requirement of the proper pricing or tariff policy to meet the adequate revenue for the utility is essential to achieve and often conflicting objectives; efficient resource use, secure an adequate revenue and ensure equity for stakeholders. Equity for the customer has been a major concern in the existing tariff structure as minority of the tariff categories have to pay extra high prices, majority to enjoy the facilities with highly subsidized prices. Florio, (2007) concluded in a study while highlighting the important of policies in energy sector with a careful monitoring of the trends in prices and in users' spending. Because this is very vital for the electricity sector as the electricity is one of the key area where almost all the sectors would change. The changes would introduced have to be carefully analyzed.

\section{Discussion}

Since the BIPV electricity generation has relationship with the electricity tariff trade-off between the grid electricity cost and the unit cost of electricity generates from BIPV facility is vital in electricity prosumers point of view. In contrast the marginal cost of electricity generation is important to the utilities point of view on solar electricity generation. The Solar FIT cost has to compare with the incremental generation cost of the CEB. Without considering, the technical requirement if any unit marginal cost is greater than the purchasing unit cost of solar roof top generation the encouragement of BIPV is justifiable. Hence, the presence of any unit of electricity having higher marginal cost in the dispatch than the Solar Roof Top purchasing price the payment for solar is can be justifiable. Under the prevailing situation other than the generation sources where unit cost is less than LKR $22 / \mathrm{kWh}$ is competitive with solar roof top generation. Hence in the process of meeting electricity demand in the day time in either wet or Dry season solar roof top is economical for the utility as an energy generation source as all the thermal power generation options are expensive than solar roof top FIT other than the Coal. However, it should be noted that during the wet season there may be less amount of electricity would generate from solar roof top systems. However, in the wet weather condition CEB can generate larger percentage of required amount of electricity from hydro power plants.

When come to the context of using net metering facility by high end customers bring their cost down is economically unfavorable for the utility. As per the prevailing tariff method CEB has mechanism to get cross subsidiary from the high end customers to ameliorate the impact of concessionary tariff policy implemented to 
the majority of the electricity customers such as domestic customers, industrial customers so and so forth. The impact of Solar roof top program on cross subsidiary is not because of purchasing of electricity from BIPV, it is because of misconception of tariff mechanism. Basically any government targets concessionary policies for the citizens of the Country who need assistance from the government. But in Sri Lankan tariff mechanism the concessions flow even to the customers who do not qualify for such concession. The present tariff structure is a creature of the government policy and hence it is the responsibility of the government to bear the cost of this policy; and hence it is the responsibility of the government to bear the cost of this policy to the Utility. Assad et al., 2015 stressed to use multi-criteria decision-making methods for integration and mainly such decision would be made on subjectively (Assad et al., 2015). This is applicable for Solar BIPV program of Sri Lanka. Hence other criteria also important such as technical constraints so and so forth and should be considered for decision-making process of the program.

\section{Conclusion}

There is a global trend to adopt sustainable concepts in existing buildings, future building designs so and so forth. Concepts such as indoor quality and energy efficiency techniques apply to enhance the performance of building in order to reduce operating costs. In that context, increasingly, all customers would be compelled to install BIPV for electricity generation with their own funds. Since Customers use different reasons for BIPV decision making, GOSL and CEB has to consider the financial impact of the program. But this analysis reveals that the criteria for justification of FIT has to be assessed with the marginal electricity generation cost of each technology responsible for meeting demand in the day peak. Finally, it can be concluded that Solar Roof Top program FIT mechanism introduced to the electricity customers has no any financial impact on electricity Utility that is CEB other than the net metering method. That is also not a negative impact of the program, it is mainly because of the existing tariff method of the Country. Therefore, rather than passing the blames to the Solar Roof Top program it is wise to review the electricity tariff policy of Sri Lanka to target the concession directly to the needy people. Based on these findings, this paper put forward corresponding policy recommendations.

\section{References}

Abu-Rub, H., Iqbal, A., Amin, S., Abdelkadar, G., Salem, N., Mansoor, S., Mirza, T., \& Ahmed, S. (2010). Feasibility analysis of solar photovoltaic array cladding on commercial towers in Doha, Qatar-a case study. International Journal of Sustainable Energy, 29(2), 76-86. https://doi.org/10.1080/14786460903406590

Florio, M. (2007). Electricity prices as signals for the evaluation of reforms: an empirical analysis of four European countries. International Review of Applied Economics, 21(1), 1-27. https://doi.org/10.1080/02692170601034093

Hammon, R.W. (2010). Applications for Large Residential Communities: What is Net-zero Energy? Strategic Planning for Energy and the Environment, 29(3), 26-55. https://doi.org/10.1080/10485231009595086

Hanzlik CEM A.R. (2010) Developing Solar Photovoltaic for Competitively Priced Energy. Cogeneration \& Distributed Generation Journal. https://doi.org/10.1080/15453669.2010.9914398

Hossain, S. M. (1993). Pricing Reforms and Divestiture in the Electricity Sector of Bangladesh. The Bangladesh Development Studies, 1-23.

Kosugi, T., Shimoda, Y., \& Tashiro, T. (2019). Neighborhood influences on the diffusion of residential photovoltaic systems in Kyoto City, Japan. The Environment Economics and Policy Studies. https://doi.org/10.1007/s10018-019-00239-5

Kristov, L. (1995). The price of electricity in Indonesia. Bulletin of Indonesian Economic Studies, 31(3), 73-101. https://doi.org/10.1080/00074919512331336835

Leal, V. M., Granadeiro, V., Azevedo, I., \& Boemi, S. N. (2015). Energy and economic analysis of building retrofit and energy offset scenarios for Net Zero Energy Buildings. Advances in Building Energy Research, 9(1), 120-139. https://doi.org/10.1080/17512549.2014.944567

Levi, M., Economy, E. C., O'Neil, S., \& Segal, A. (2010). Globalizing the Energy Revolution-How to Really Win the Clean-Energy Race. Foreign Aff. 89.111.

Lin, B., \& Jiang, Z. (2011). Estimates of energy subsidies in China and impact of energy subsidy reform. Energy Economics, 33(2), 273-283. https://doi.org/10.1016/j.eneco.2010.07.005

Mondol, J. D., \& Hillenbrand, S. K. (2014). Grid parity analysis of solar photovoltaic systems in Europe. International Journal of Ambient Energy, 35(4), 200-210. https://doi.org/10.1080/01430750.2013.820141 
Roach, C. R. (2017). Simply Electrifying: The Technology that Transformed the World, from Benjamin Franklin to Elon Musk. Benbella Books.

Sinha, S. (2005). Introducing competition in the power sector: open access and cross subsidies. Economic and Political Weekly, 40(7), 631-637.

Solar Resource Atlas. (2014). Sri Lanka Sustainable Energy Authority.

Temby, O., Kapsis, K., Berton, H., Rosenbloom, D., Gibson, G., Athienitis, A., \& Meadowcroft, J. (2014). Building-integrated photovoltaics: distributed energy development for urban sustainability. Environment: $\begin{array}{lllll}\text { Science and Policy for Sustainable Development, } & 56(6), & \text { 4-17. }\end{array}$ https://doi.org/10.1080/00139157.2014.964092

Wiginton, L. K., Nguyen, H. T., \& Pearce, J. M. (2010). Quantifying rooftop solar photovoltaic potential for regional renewable energy policy. Computers. Environment and Urban Systems, 34(4), 345-357. https://doi.org/10.1016/j.compenvurbsys.2010.01.001

Wong, P. K., Barr, R. A., \& Kalam, A. (2015). Generation modelling of residential rooftop photovoltaic systems and its applications in practical electricity distribution networks. Australian Journal of Electrical and Electronics Engineering, 12(4), 332-341. https://doi.org/10.1080/1448837X.2015.1092928

Yang, R. J., \& Zou, P. X. (2016). Building integrated photovoltaics (BIPV): Costs, benefits, risks, barriers and improvement strategy. International Journal of Construction Management, 16(1), 39-53. https://doi.org/10.1080/15623599.2015.1117709

Zandler, H., Mislimshoeva, B., \& Samimi, C. (2016). Scenarios of solar energy use on the "roof of the world": potentials and environmental benefits. Mountain Research and Development, 36(3), 256-266. https://doi.org/10.1659/MRD-JOURNAL-D-15-00077.1

\section{Copyrights}

Copyright for this article is retained by the author(s), with first publication rights granted to the journal.

This is an open-access article distributed under the terms and conditions of the Creative Commons Attribution license (http://creativecommons.org/licenses/by/4.0/). 